\title{
Democracia, Saúde Pública e Universalidade: o difícil caminhar
}

\section{Democracy, Public Health and Universality: a hard walk}

Rosa Maria Marques

Professora Titular da Pontifícia Universidade Católica de São Pau-

lo, especialista em políticas sociais e ex-presidente da Sociedade Brasileira de Economia Política (1998 e 2002).

Endereço: Rua Cayowá, 560 apt. 112, Cep 05018.000, São Paulo, SP, Brasil.

E-mail: rosamarquesळhipernet.com.br

\section{Áquilas Mendes}

Professor do Departamento de Economia da Pontifícia Universidade Católica de São Paulo e da Faculdade de Economia da Fundação Armando Álvares Penteado, de São Paulo, vice-presidente da Associação Brasileira de Economia da Saúde.

Endereço: Rua Pedroso Alvarenga, 401 apt. 131, Cep 04531-010, São

Paulo, SP, Brasil.

E-mail: aquilasn®uol.com.br

\section{Resumo}

Este artigo analisa os determinantes e as condicionalidades do processo de universalização da saúde pública dos países desenvolvidos, especialmente os europeus, e do Brasil, visando salientar suas diferenças. Na primeira parte, em que são apresentadas as principais interpretações sobre a construção do Welfare State, enfatiza-se as características daquele momento histórico e sua articulação com o padrão de acumulação dominante. Para isso, foi revisitada a literatura principal sobre o assunto, tanto em relação ao processo de construção dos sistemas de proteção, quanto ao chamado padrão fordista de acumulação. Na segunda parte, voltada para o entendimento das condições nas quais se definiu a universalidade das ações de serviço de saúde no Brasil, se destaca que as condições gerais do capitalismo não são mais aquelas do período do pós-guerra; salienta-se que o novo ambiente interage e constrange a trajetória brasileira, principalmente quanto à ação de seu Estado e enfatiza-se que a desigualdade constitui marca indelével da sociedade brasileira, o que poderia ser visto como uma dificuldade para a aplicação da universalidade no país. Para essa parte, novamente a pesquisa priorizou o conhecimento acumulado na literatura, em especial na econômica. Embora de maneira desigual, mesmo com esse constrangimento, dados empíricos indicam que houve avanços na condição de saúde da população brasileira após o surgimento do Sistema Único de Saúde (SUS), especialmente com o Programa de Saúde da Família (PSF). Palavras-chave: Determinantes de Saúde; Desigualdade; Universalidade; Padrão de Acumulação. 


\section{Abstract}

This article analyses the determinants and the elements that condition the universalization process of public health in developed countries, especially in the European ones, and in Brazil, in order to outline their differences. The first part presents a selection of the main theories about the emergence of the Welfare State. Based on literature, it approaches the characteristics of that particular historic period and its articulation with the dominant capitalist accumulation pattern. The second part explains the conditions in which universal health services and actions in Brazil were defined. It is argued that the general conditions of capitalism are no longer the ones built in the post-war period. The new environment interacts and restrains the Brazilian process, mainly regarding the action of its State. It is emphasized that inequality is an important label of the Brazilian society, which could be seen as a barrier to implement the principle of universal health in the country. Even with the presence of inequality aspects, some advances in the health condition of the Brazilian population, according to the present study, have been reached after the emergence of SUS (the Brazilian National Health System), mainly with the Family Heath Program.

Keywords: Determinants of Health; Inequality; Universality; Accumulation Pattern.

\section{Introdução}

A adoção do direito à universalidade das ações e serviços de saúde deve ser pensada a partir da construção do Estado democrático de direitos. Isso porque a universalidade constitui um princípio desse Estado, que garante a cobertura dos riscos sociais de sua população. No mundo, esse princípio teve sua expressão maior no Welfare State (WS), resultado de um longo processo de construção.

Sabe-se que na maior parte das vezes em que esse princípio é discutido "seja com a finalidade de defendê-lo, seja para pronunciar sua inviabilidade e a necessidade de estabelecer outras bases para a proteção social “, ele aparece como produto do crescimento econômico vivenciado pelos países capitalistas desenvolvidos, que se seguiu ao fim da Segunda Guerra Mundial. Essa associação é feita tanto pelos analistas e pesquisadores como por aqueles que escutam ou lêem suas contribuições.

Embora essa associação não esteja completamente equivocada, sua redução ao período de crescimento econômico dos trinta anos gloriosos ${ }^{1}$, assim chamado na literatura francesa, obscurece seu processo de construção e não permite que se dimensione quais foram os fatores que facilitaram sua adoção. Ao se salientar quase que exclusivamente o aspecto econômico, tomase o resultado como determinante, não facilitando a compreensão das dificuldades da implantação da universalidade em países com estrutura diferente daqueles, tais como os da América Latina. Contudo, mesmo se restringíssemos a análise ao plano econômico, ficaria claro que a distância é enorme entre a realidade econômica do pós-guerra dos países desenvolvidos e a do Brasil após a Constituição de 1988.

Este artigo analisa os fatores que moldaram o processo de universalização da saúde pública nos países desenvolvidos, especialmente nos europeus, e no Brasil, assim como as condições em que isso se realizou, visando destacar as diferenças entre os dois processos. Para isso, na primeira parte, dedicada à construção do WS, além de se apresentar os traços gerais das principais teorias que buscam explicar sua construção e de se oferecer uma interpretação alternativa,

1 Na literatura econômica, os trinta anos gloriosos referem-se ao período entre 1950 e 1970, em que os países capitalistas centrais apresentaram taxas de crescimento econômico significativas, jamais obtidas nas distintas fases da história do capitalismo. 
descreve-se as características de seu momento histórico e a sua articulação com o padrão de acumulação dominante.

Na segunda parte, aborda-se o caso brasileiro. Trata-se, em primeiro lugar, de entender as condições em que se definiu a universalidade das ações de serviço de saúde no Brasil, iniciando-se com o Sistema Único de Saúde (SUS) e com a Seguridade Social, com destaque para o momento político de seu surgimento. Em segundo lugar, apontam-se as condições gerais do capitalismo, que não eram mais aquelas do período do pós-guerra, indicando como esse novo ambiente interagiu e constrangeu a trajetória brasileira, principalmente quanto à ação de seu Estado, enfatizando que a desigualdade constitui herança histórica da sociedade brasileira, o que dificulta a aplicação da plena universalidade. Por último, destaca-se que, apesar dos constrangimentos econômicos, foram observados avanços na condição de saúde da população brasileira.

\section{A Construção da Proteção Social como um Direito Universal nos}

\section{Países Desenvolvidos}

\section{Diferentes teorias explicativas}

O WS compreende um conjunto de políticas públicas que visa prover a cobertura dos riscos advindos da invalidez, da velhice, da doença, do acidente de trabalho e do desemprego. Na literatura especializada, sua origem e desenvolvimento são atribuídos a diferentes causas. De maneira geral, pode-se agrupá-las em duas grandes linhas explicativas: a que atribui principalidade à ordem econômica e a que considera os fatores políticos como os determinantes. Os defensores da primeira interpretação entendem o WS como uma necessidade decorrente das mudanças provocadas pela industrialização ou como resposta às demandas de acumulação e legitimação do sistema capitalista. Já entre os que atribuem importância ímpar aos condicionantes de ordem política, encontram-se os que consideram o WS resultado ou da ampliação progressiva de direitos ou do acordo entre o capital e o trabalho organizado, ou de configurações históricas particulares de estruturas estatais e instituições políticas.

Os principais autores que entendem o WS como resposta às mudanças, provocadas pela industrializa- ção, são: Wilensky e Lebeaux, Richard Titmuss e Thomas H. Marshall. Para Wilensky e Lebeaux, os programas sociais foram construídos na medida em que a industrialização alterou radicalmente a vida familiar, concedendo novos papéis a seus integrantes e diminuindo sua capacidade de determinar a reprodução da força de trabalho. Foram elementos-chave da promoção da coesão e integração social da nova sociedade em formação, e sua implantação só foi possível em função do excedente gerado e acumulado na industrialização. Já o desenvolvimento do WS foi determinado por fatores culturais, explicando as diferenças existentes entre países (Wilensky e Lebeaux, 1965).

Titmuss $(1962 ; 1974 ; 1976)$ atribui a ampliação dos programas sociais à crescente divisão do trabalho propiciada pela industrialização. Para Marshall (1967; 1967a), tanto a origem como o desenvolvimento do WS são atribuídos à evolução lógica e natural da própria ordem social, decorrente da industrialização.

Entre os que analisam o WS como resposta às necessidades de acumulação e de legitimação do sistema capitalista, encontram-se O'Connor (1973) e Offe (1994). Consideradas as condições econômicas e sociais decorrentes da industrialização, o grau de variabilidade dos programas sociais seria pequeno. O WS cumpriria a função de corrigir/compensar (des)funcionalidades criadas pela acumulação capitalista no plano social. Visto de outro ângulo, seria a contrapartida necessária para o bom andamento do sistema capitalista.

Entre os autores que dão principalidade aos condicionantes políticos, entendendo o WS como resultado da ampliação progressiva dos direitos, novamente é dado lugar de destaque a Marshall (1967). Para ele, na medida em que o continuum " de direitos civis para políticos, e de direitos políticos para sociais “é parte integrante do próprio construir do conceito de cidadania na sociedade capitalista, os programas sociais públicos expressariam o corolário desse processo. Vários outros autores desenvolvem suas análises a partir desse entendimento. Entre eles se destaca Rosanvallon: "Os direitos econômicos e sociais aparecem naturalmente como um prolongamento dos direitos civis" (1983, p.23). Apesar dessa afirmação, o autor salienta que é o movimento democrático e igualitário iniciado no século XVIII quem reivindica a ampliação do escopo compreendido na idéia de cidadania. De natural, portanto, resta pouco. 
A compreensão do WS como produto de um acordo entre o capital e o trabalho organizado é representada por Gough (1979) e Esping-Andersen (1985, 1985a). Segundo Gough, o WS corresponde a um determinado estágio de desenvolvimento do sistema capitalista e, tal como O'Connor (1973), entende que seus programas cumprem função de auxiliar no processo de acumulação, de reproduzir a força de trabalho e de legitimar o sistema. Mas ao reconhecer a ausência de automatismo no surgimento de leis que garantissem a realização dessas funções, distancia-se de O'Connor. O mesmo ocorre quando aponta que a expansão do WS está condicionada à dinâmica da acumulação e à capacidade de financiamento dos programas sociais. A pressão exercida pelas classes subordinadas e pelos outros grupos organizados a elas associadas, bem como o seu grau de organização, é decisiva para a introdução das medidas de proteção social e, inclusive, para a determinação do grau de centralização das políticas sociais. Dessa forma, o desenvolvimento do WS pode ser visto como expressão do acordo realizado entre capital e trabalho nos anos que se seguiram ao fim da Segunda Guerra Mundial. Embora enfatize a importância das condições de financiamento para a manutenção do WS, depreende-se de sua análise que a expansão ou retração das políticas sociais é principalmente função da relação de forças entre os agentes que realizaram esse acordo.

A importância do grau de organização dos trabalhadores é bem apreendida por Esping-Andersen. Além de dizer que as diferenças existentes entre os sistemas de proteção são determinadas pela diversidade do peso social ativo que os trabalhadores assumem em cada sociedade, atribui a suas lideranças a consciência de que a implementação dos programas sociais significa, entre outras, a possibilidade de (des)mercantilizar parte do custo de reprodução da força de trabalho.

Entre os autores que concedem um peso relativamente importante aos condicionantes políticos há, ainda, os que vêem o WS como resultado de configurações históricas particulares de estruturas estatais e instituições políticas. São eles: Heclo (1974), Skocpol (1992), Orloff (1993) e Weir e col. (1988). Para eles quase não há lugar para variáveis que não sejam o Estado, enfatizando dessa forma o estudo detalhado de cada país, o que prejudica o entendimento mais abrangente do fenômeno.

\section{Da solidariedade de classe à solidariedade sistêmica}

Quase todas as teorias mencionadas anteriormente não fazem distinção entre a proteção social existente antes do final da Segunda Guerra Mundial e o WS, e tendem a eleger uma variável independente como única explicativa do fenômeno. Mas uma variável pode, na melhor das hipóteses, assumir principalidade, sendo, portanto, um equívoco atribuir importância ou aos fatores econômicos ou aos fatores políticos, alternadamente. Esse enfoque não permite analisar como os diferentes fatores interagem entre si, perdendo-se parte da riqueza do processo de construção e de desenvolvimento da proteção social.

\section{Primeira fase}

A formação histórica dos sistemas de proteção social confunde-se com a própria construção da sociedade salarial. Em suas origens, encontram-se os mecanismos criados pelos trabalhadores assalariados da indústria, que constituíam amparo de tipo “ajuda mútua”. Formados pelos trabalhadores da indústria, visavam prover necessidades derivadas do desemprego, da doença, da morte e da velhice (Castel, 1995). Essas formas rudimentares e corporativistas de proteção buscavam cumprir dois objetivos: 1) preencher o vazio ocasionado pela destruição das antigas formas de solidariedade associadas às corporações de ofício e à vida no campo, provocado pelo rápido crescimento da indústria e das cidades; 2) servir como garantia mínima para que os trabalhadores pudessem não ficar completamente à mercê das condições de trabalho e salário oferecidas pelos capitalistas. Dessa forma, a existência desse tipo de proteção social, bem como sua capacidade em prover a cobertura que se propunha, dependiam diretamente do grau de organização que os trabalhadores, reunidos por ramos de atividade, lograram alcançar nas fases iniciais do processo de industrialização.

Na época, a única ação realizada pelo Estado, com o concurso decisivo da iniciativa privada, resumia-se às "casas de trabalho", que longe de constituírem instrumento de integração ou de assistência social, representavam uma poderosa ferramenta para disciplinar a força de trabalho (Ibid). Mais tarde, dada a omissão do Estado, alguns empresários preocuparam-se em garantir uma cobertura mínima dos principais riscos e necessidades de seus trabalhadores. As ações desen- 
volvidas pelos industriais abrangiam, inclusive, o fornecimento de moradia e educação para os filhos dos trabalhadores. De acordo com alguns autores, dos quais se destaca Coriat (1982), esse tipo de proteção permitia que o capitalista fixasse e disciplinasse sua força de trabalho. 0 Estado somente passou a se responsabilizar pela organização e gestão da proteção social impulsionado pelo crescimento da organização independente dos trabalhadores (Esping-Andersen, 1991). Isso ocorreu no início do século XX, fase que corresponde à gestão taylorista da força de trabalho. A única exceção de que se tem registro é o caso da Alemanha, onde a legislação previdenciária data dos anos 1880 , século XIX. Esse fato, no entanto, apenas vem confirmar a relação existente entre a emergência do Estado em matéria de proteção social e o grau de organização dos trabalhadores, pois se há lugar onde a social-democracia havia se enraizado profundamente entre a população era na Alemanha (Broué, 1971).

Aceitar que o Estado tenha apenas se preocupado em organizar sistemas de proteção social pressionado pela organização dos trabalhadores não implica desconsiderar que esses sistemas tiveram um papel na própria formação do assalariamento. Segundo Lenhardt e Offe (1984) “(...) do ponto de vista sociológico, nada indica que os indivíduos atingidos por essa desapropriação das condições de utilização do seu trabalho ou de outras condições de subsistência transitem espontaneamente para o estado da proletarização ativa, isto é, passem a oferecer sua força de trabalho nos mercados de trabalho" (p. 15 e p. 16). Entre outras alternativas, havia a da mendicância, do roubo e da emigração para outras terras. 0 trabalho assalariado torna-se atraente somente quando os riscos a ele associados são cobertos.

O desenvolvimento desigual da indústria e da organização dos trabalhadores faz com que o início da participação do Estado ocorresse em momentos diferentes em vários países. Já o processo de incorporação dos riscos foi mais ou menos semelhante em todos os países, havendo uma clara precedência do acidente de trabalho, da velhice e da invalidez sobre os demais. De fato, a garantia de benefícios decorrentes de acidente de trabalho está na origem da estruturação dos atuais sistemas de proteção.

A cobertura atingia apenas os trabalhadores urbanos e o financiamento fundava-se nas contribuições de empregados e empregadores. 0 regime de custeio era de capitalização coletiva, isto é, o fundo acumulado era utilizado para o pagamento das pensões e aposentadorias dos contribuintes de acordo com a disponibilidade decorrente da rentabilidade de seus ativos. Não havia, portanto, benefícios definidos. Nessa forma de organização da proteção, a solidariedade, de caráter compulsório, era estabelecida entre os próprios ativos (Olivennes, 1992).

\section{Segunda fase}

A segunda fase da construção dos sistemas de proteção iniciou-se ao término da Segunda Guerra Mundial, quando o regime fordista de acumulação - mudanças no processo de trabalho que sustentaram a produção em série - tornou-se hegemônico no mundo. Apesar das diferenças nacionais, suas características básicas eram a ampliação paulatina da cobertura para novos segmentos de trabalhadores ou populacionais e a incorporação de novos riscos e problemas sociais como objeto de sua ação. É próprio do WS, portanto, a universalização da cobertura para o conjunto da população e o alargamento do próprio conceito de proteção. Na área previdenciária, houve a substituição da capitalização coletiva pela repartição simples, significando a introdução da solidariedade entre gerações e o abandono da solidariedade entre os ativos. No campo da saúde, a assistência fechada " aquela derivada da importância política e financeira de determinados setores de trabalhadores " foi substituída pela assistência pública, tornada cada vez mais universal. Nos diferentes países, essa garantia foi estruturada de diversas maneiras, desde a exclusiva atenção do setor público a situações em que o usuário podia recorrer ao setor privado, mediante reembolso parcial variável.

A universalização da cobertura implicou na superação da proteção social voltada para os trabalhadores assalariados e urbanos e na eleição da cidadania como princípio para a concessão dos direitos. Uma das conseqüências dessa profunda modificação foi o uso, cada vez mais significativo, das receitas fiscais no interior de sistemas basicamente dependentes das contribuições sobre a folha salarial. A garantia de renda e serviços, independentemente da capacidade de contribuição do beneficiário e a participação de recursos públicos no financiamento dos sistemas de proteção tornaram difusa a separação entre proteção e seguro social. 
Os anos 1950 e 1960 foram marcados por grandes transformações nas estruturas econômicas e sociais. Segundo Hobsbawm (1995), esse período corresponde a uma fase excepcional na história do capitalismo, talvez único. $\mathrm{O}$ crescimento do Produto Nacional Bruto (PNB) dos países desenvolvidos bate todos os recordes anteriores e a indústria expande-se por toda a parte. 0 crescimento acelerado do investimento "sustentado na realização de elevadas taxas de lucro "permite que o emprego aumente como nunca, apesar dos ganhos de produtividade propiciados pelas inovações tecnológicas que marcaram esse período. A necessidade de força de trabalho era tanta que, esgotados os bolsões tradicionais de reserva, a mulher passou a compor definitivamente o mercado de trabalho. Nos países desenvolvidos, o assalariamento com direitos passou a ser a norma.

Em relação ao Estado, governos de todos os matizes políticos adotaram o planejamento, embora com ênfase diferenciada, e consideraram legítima a intervenção do Estado na economia e na determinação das condições de existência da classe trabalhadora.

No plano político, fundamental para o processo de decisão, foi determinante o papel desempenhado pela então União Soviética na derrota da Alemanha nazista, o surgimento de outros Estados socialistas no Leste e a importância das representações políticas dos trabalhadores na composição de vários governos (Przeworski, 1989; Hobsbawm, 1992). Ao se levar em conta esse último fator, considera-se que o WS também serviu como anteparo para impedir o recrudescimento das lutas sociais nos países ocidentais após o fim da Segunda Guerra Mundial.

\section{A articulação do welfare state com o padrão de acu- mulação capitalista}

Segundo algumas escolas de pensamento, os benefícios e ações concedidos pela proteção social e a política de aumento real dos salários e a expansão do crédito ao consumidor foram a contrapartida necessária para a generalização das normas de produção que viabilizaram a produção em série (Aglietta, 1979; Coriat, 1982). Ao mesmo tempo o WS constituiu peça-chave desse período do capitalismo, pois auxiliou na implantação de uma forma particular de gestão da força de trabalho, uma das bases da acumulação fordista.

No plano geral, foi um dos fatores que auxiliou a quebrar a resistência dos trabalhadores aos métodos fordistas e garantir que não houvesse conflitos maiores. Na unidade produtiva, a gestão da força de trabalho caracterizava-se pela estabilidade do emprego e pela concessão de aumentos reais de salário; no plano social, pelo conjunto de garantias propiciadas pelo WS, pela regulamentação do trabalho e pelo reconhecimento dos sindicatos como representantes legítimos da classe trabalhadora.

O valor relativamente expressivo dos benefícios e a incorporação de novos riscos sociais permitiram que o salário deixasse de ser o único elemento constitutivo da renda disponível da população assalariada. Passaram a compor o custo de reprodução do trabalhador os benefícios sociais concedidos às famílias ou ao trabalhador, tanto sob a forma de serviços como por meio de pensões, auxílios e reembolsos de despesas, especialmente na área da saúde. Em alguns casos, como na França, em 1990, a participação das transferências realizadas pelo WS chegou a representar mais de 30\% da renda disponível das famílias (D‘IIntignano, 1993).

Assim, durante o período de consolidação do WS, foi concertada uma relação peculiar entre capital e trabalho. Na empresa, o acordo estabelecido contava, de um lado, com a garantia de emprego e aumentos reais de salário e, de outro, com a produção a altas taxas de produtividade, viabilizadas pela implantação da organização científica do trabalho. No plano social, fazia parte desse concerto a generalização e o aprofundamento da cobertura da proteção social.

O papel desempenhado pelos sindicatos e pelos partidos tradicionais dos trabalhadores nesse acordo foi fundamental. Se de um lado sua participação significou que o Estado e o capital os reconheciam como legítimos representantes dos trabalhadores, por outro, isso permitiu que as reivindicações fossem canalizadas para estes organismos. Isso propiciou certa previsibilidade e controle nas relações com os trabalhadores. Esse controle foi ainda mais acentuado quando eles passaram a privilegiar o aumento real de renda, fosse pelo salário direito ou indireto. Desde que a expansão da acumulação fosse acompanhada de aumento de salários reais e de uma crescente cobertura dos riscos sociais, não haveria atritos maiores entre capital e trabalho.

Dessa forma, a proteção social era absolutamente adequada aos interesses da acumulação fordista. Além de fixar o trabalhador na empresa e de viabilizar o 
consumo de massa, concedia previsibilidade nas relações com os trabalhadores.

\section{A Universalidade como Expressão do Desejo da Construção de uma Sociedade Democrática: o caso brasileiro}

\section{Características estruturais do Sistema Único de Saúde (SUS) e da seguridade social}

Na segunda metade da década de 1980, a discussão e a elaboração de uma nova Constituição mobilizaram totalmente as atenções da nação, pois estava em jogo a definição das bases que iriam sustentar o desenvolvimento do novo regime. Entre essas bases, a questão social assumia importância ímpar, pois se fazia necessário resgatar a enorme dívida social herdada do período militar. Com esse propósito, os constituintes escreveram na Constituição de 1988 a garantia de direitos básicos e universais de cidadania, estabelecendo o direito à saúde pública, definindo o campo da assistência social, regulamentando o seguro-desemprego e avançando na cobertura da previdência social. Essas garantias foram objeto de capítulo específico o da Seguridade Social, simbolizando o rompimento com o passado.

Os princípios que animaram os setores progressistas da constituinte foram: ampliação da cobertura para segmentos até então desprotegidos; eliminação das diferenças de tratamento entre trabalhadores rurais e urbanos; implementação da gestão descentralizada nas políticas de saúde e assistência; participação dos setores interessados no processo decisório e no controle da execução das políticas; definição de mecanismos de financiamento mais seguros e estáveis; e, garantia de um volume suficiente de recursos para a implementação das políticas contempladas pela proteção social, entre outros objetivos. No campo da Previdência Social, esses princípios resultaram principalmente na criação de um piso de valor correspondente ao do salário mínimo e na eliminação das diferenças entre trabalhadores rurais e urbanos referente aos tipos e valores de benefícios concedidos. A Cons- tituição de 1988 manteve, tal como antes, separadas a previdência dirigida aos trabalhadores do mercado formal do setor privado da economia e a dos servidores federais, estaduais e municipais.

Alguns avanços no sentido da universalização, da ampliação da cobertura e da diminuição das desigualdades antecederam a Constituição de 1988. Na previdência, especificamente entre 1985 e 1987, durante o governo de José Sarney, o valor dos pisos dos benefícios urbanos foi aumentado, o prazo de carência diminuído e alguns tipos de benefícios foram estendidos para a clientela rural. A criação do SUS no novo texto constitucional resultou, sem dúvida, de um longo processo de embates entre diversos setores da sociedade, a partir do qual, já desde os anos 1970, operava-se um movimento de crescente expansão do acesso aos serviços de saúde, embora de forma "fragmentada e seletiva" e, desde os anos 1980, introduzia-se na agenda pública a questão da descentralização do sistema de saúde enquanto tema prioritário, pela formulação do Programa Nacional de Serviços Básicos de Saúde, o PREV-SAÚDE. É fundamentalmente por meio da estratégia das Ações Integradas de Saúde " que nasce originalmente como mero programa do Inamps “, aprofundada no período da Nova República com a criação do Sistema Unificado e Descentralizado de Saúde (SUDS), que a descentralização e a universalização do acesso ganham progressiva viabilidade, na medida em que fortalecem o ingresso, na arena da reforma sanitária, de atores políticos fundamentais para a consolidação desse processo: inicialmente, os governadores e, a partir do movimento de "municipalização" setorial, alguns prefeitos.

Entretanto, ainda que sendo fruto desse longo processo, a constituição do SUS pressupõe uma ruptura definitiva com o modelo anterior, tendo em vista que: (i) por meio da instituição do direito universal e integral à saúde, elimina-se a característica histórica da segmentação de clientelas do sistema de proteção social brasileiro; (ii) rompe-se, ainda, por meio dele, o modelo de financiamento anteriormente vigente, baseado fundamentalmente em contribuições individuais; (iii) introduz-se constitucionalmente uma reorganização político-administrativa de peculiar profundidade, tendo em vista que, segundo a Constituição, “as 
ações e serviços públicos de saúde integram uma rede regionalizada e hierarquizada e constituem um sistema único", organizado de acordo com as diretrizes da descentralização, atenção integral e a participação da comunidade; e (iv) define-se como complementar a participação dos prestadores de serviços privados nesse novo sistema. É, portanto, necessariamente árduo o processo de implementação de uma transformação dessa natureza e magnitude, que requer não só mudanças político-institucionais, organizacionais, culturais e financeiras, como na própria concepção do modelo de atenção à saúde.

A instituição do acesso universal à saúde, como um direito inerente à cidadania, foi coerentemente acompanhada da inserção do setor saúde no Sistema de Seguridade Social e, ainda, do financiamento setorial por meio do Orçamento da Seguridade Social e dos Tesouros Federal, Estaduais e Municipais. A própria composição do Orçamento da Seguridade Social “ sem vincular fontes para cada área específica " contemplou a natureza distinta dos benefícios e serviços por ele financiados. Para garantir o financiamento das despesas de proteção social, ampliadas pela adoção da Seguridade Social, mas também para tornar o financiamento menos dependente das variações cíclicas da economia (principalmente do emprego junto ao mercado formal de trabalho), os constituintes definiram que seus recursos teriam como base o salário (contribuições de empregados e empregadores), o faturamento (trazendo para seu interior o Fundo de Investimento Social - Finsocial, que deu lugar, em 1991, à Contribuição para o Financiamento da Seguridade Social, Cofins e o Programa de Integração Social e de Formação do Patrimônio do Servidor Público “PIS/ Pasep), o lucro líquido das empresas (contribuição nova introduzida na Constituição, denominada Contribuição sobre o Lucro Líquido “ CLL) e a receita de concursos e prognósticos. Além dessas fontes, a seguridade contaria com recursos de impostos da União, Estados e Municípios. Ainda, ao se constituir um orçamento unificado, pretendeu-se racionalizar a alocação de recursos do Orçamento da Seguridade Social (OSS), evitando a pulverização no uso de receitas de fundos previamente existentes. Por meio de lei complementar, dispôs-se que 30\% dos recursos do OSS deveriam ser destinados ao SUS. A esses recursos, de origem federal, deveriam ser acrescidas, segundo a Consti- tuição, receitas provenientes dos Tesouros Estaduais e Municipais, que viabilizassem a implementação desse sistema. A Constituição de 1988 não definia, entretanto, como seria a participação dos entes federados no financiamento da Seguridade Social. Em 1997, foi criada a Contribuição Provisória sobre a Movimentação Financeira (CPMF), cujos recursos se somaram àqueles definidos na Constituição. Somente em 13 de setembro de 2000 foi aprovada a Emenda Constitucional $n^{0} 29$, estipulando a forma da inserção da União, dos Estados e dos Municípios no financiamento do Sistema Único de Saúde.

Os constituintes também tiveram o cuidado de definir que as contribuições sociais e os recursos dos entes governamentais seriam de uso exclusivo da Seguridade Social. Infelizmente nenhum governo que se seguiu à promulgação da Constituição de 1988 cumpriu esse dispositivo.

Outro aspecto do financiamento da Seguridade Social que foi alvo da atenção dos constituintes e que está extremamente relacionado com a concepção de proteção social pensada no auge da democratização do país é o entendimento de que não caberia a existência de vínculo entre fonte e uso no interior da Seguridade Social. Essa compreensão decorria do próprio conceito holístico de proteção social, em que é impensável a cobertura de um risco, sem a garantia da cobertura do outro. Dessa forma, a cada ano, quando da discussão do orçamento, seria definida a partilha do conjunto de receitas previstas para os diferentes ramos da Seguridade Social. A única vinculação prevista foi a dos recursos do PIS/Pasep, que é dirigida apenas para o programa seguro-desemprego e para o pagamento do abono PIS/Pasep.

A universalização de direitos e a participação da comunidade na definição das políticas sociais tiveram como princípio fundador a superação do caráter meritocrático e a adoção da cidadania como critério de acesso. A cidadania é facilmente reconhecível na área da saúde. De uma situação em que o serviço público era voltado apenas aos trabalhadores contribuintes do mercado formal, passou-se à garantia do direito para todos. Já na Previdência Social, esse critério ficou imbricado ao anterior: paralelamente aos trabalhadores contribuintes com aposentadoria calculada basicamente a partir de suas contribuições, coexistem os trabalhadores rurais e as pessoas com salários 
muito baixos, aos quais é garantido o piso de um salário mínimo.

\section{0 movimento que conduziu ao sus}

A criação do Sistema Único de Saúde (SUS) tem sido analisada como a mais bem-sucedida reforma da área social empreendida sob o novo regime democrático. Em sua gênese, pode-se identificar a organização do expressivo movimento sanitarista em meados da década de 1970, em contexto profundamente marcado pela resistência social e política ao regime autoritário. A questão da saúde, assim como outras demandas da sociedade brasileira por liberdades civis e bens coletivos que fossem capazes de diminuir desigualdades de renda e de acesso a serviços públicos, foi um dos eixos da luta social e política durante as décadas de 1970 e 1980 (Lima e col., 2005, p.15).

A literatura brasileira é rica na documentação e na análise sobre o surgimento e o papel desempenhado pelo movimento sanitarista na luta pela universalização dos serviços e ações da saúde pública. Entre os vários autores que se debruçaram sobre esses temas, salientamos a síntese realizada por Escorel e col. (2005). Esses autores, reforçando a idéia presente na citação mencionada, chamam a atenção para o fato de o movimento sanitarista ter se estruturado no mesmo momento em que outros movimentos sociais começaram a se rearticular, ainda durante o período da ditadura militar. É durante o governo Geisel que sindicatos de diferentes categorias de trabalhadores da saúde, com destaque para os médicos, acadêmicos e pesquisadores, começam a debater vários aspectos da saúde do povo brasileiro e do serviço de saúde público e/ou previdenciário. Decorrentes desse movimento, vários seminários foram realizados e diversos grupos de trabalho foram criados. No plano organizativo, foi criada a Associação Brasileira de Pós-Graduação em Saúde Coletiva (Abrasco), em 1979, com o apoio dos Departamentos de Medicina Preventiva dos cursos de medicina. Idéias e concepções foram testadas e propostas nas secretarias de saúde em que representantes do movimento se faziam presentes.

Com a democratização do país, já no governo Sarney, lideranças do movimento assumiram postoschave nas instituições responsáveis pela definição e condução da política de saúde. É sob essa influência foi é convocada a $8^{\mathrm{a}}$ Conferência Nacional de Saúde, em 1986, tida como o momento mais significativo do movimento sanitarista, quando as estratégias e a plataforma da Reforma Sanitária foram definidas. Entre vários objetivos, estava presente o acesso dos serviços e ações de saúde para toda a população.

Mas a citação, mencionada anteriormente, também deu uma clara dimensão de quão diferentes foram o processo e o ambiente da implantação do direito à universalização da saúde pública no Brasil, em comparação aos países desenvolvidos. Parte dessas diferenças decorre do fato de o Brasil ter apenas instituído esse direito quando da promulgação da Constituição “cidadã”, em 1988. Em relação aos países desenvolvidos, essa adoção configurava-se "tardia”, tanto em relação ao tempo como em relação ao momento histórico que lhe fundamentou. Vejamos essas diferenças.

\section{"O mundo não era mais aquele"}

Ao contrário do que ocorreu nas três décadas que se seguiram ao fim da Segunda Guerra Mundial, não era mais o capital industrial que detinha o mando do processo capitalista. Desde o início dos anos 1980, não havia mais dúvida que o ressurgimento do capital produtor de juros era duradouro e que ele determinava as relações econômicas e sociais do capitalismo contemporâneo. Esse capital "busca fazer dinheiro sem sair da esfera financeira, sob a forma de juros de empréstimos, de dividendos e outros pagamentos a título da posse de ações e de lucros nascidos da especulação bem sucedida" (Chesnais, 2005, p.35).

Vários foram os fatores que determinaram a retomada do poder do capital financeiro. Entre eles destaca-se a decisão dos Estados Unidos e da Grã-Bretanha de implementar a liberação do movimento dos capitais, promover a desregulamentação de seus sistemas financeiros e implementar medidas que promovessem a centralização dos fundos líquidos, de empresas e das famílias. A esses fatores "institucionais" somouse o fato de, no início da crise (evidente para todos a partir de meados dos anos 1970), as empresas americanas localizadas no exterior terem colocado seus lucros não reinvestidos na City de Londres, dando assim início ao surgimento dos eurodólares. A essa imensa disponibilidade de capital, adicionou-se a oriunda do petróleo, os petrodólares, base dos empréstimos realizados para os países do então chamado Terceiro Mundo e, portanto, da dívida externa brasileira. 
O domínio do capital portador de juros teve grande impacto sobre o arranjo de proteção social conhecido como WS e sobre a relação capital/trabalho. Desde o início da crise, os ataques e os questionamentos ao WS intensificaram-se, não sendo poucos os países que introduziram dispositivos que dificultam o acesso à aposentadoria, aumentaram a participação do usuário no custeio das ações e serviços de saúde e limitaram a lista de medicamentos gratuitos, entre outros (Mesa-Lago, 200o). Ao mesmo tempo, o mercado de trabalho apresentava mudanças significativas com relação a sua realidade anterior. 0 desemprego, antes restrito a problemas decorrentes do sistema imperfeito de informações entre a demanda e a oferta (o chamado desemprego friccional), passou a registrar elevadas taxas no mundo desenvolvido. $\mathrm{O}$ trabalho assalariado ou por conta própria, sem nenhuma cobertura social ou trabalhista, antes característica do mercado de trabalho da América Latina e da África, tornou-se componente estrutural da realidade dos países desenvolvidos. Desde a metade dos anos 1970, os aumentos reais dos salários, característica dos anos dourados, foram esquecidos e substituídos por reajustes que promovem perda do poder de compra. A exclusão e a pobreza são significativas novamente.

O capital produtivo " sufocado pela dominação financeira " foi impelido a atuar sobre "o elo mais fraco", isto é, sobre os trabalhadores. A redução do custo da força de trabalho passou a ser primordial, tendo em vista o tamanho da punção que o capital portador de juros retirou do excedente criado na produção. 0 capital produtivo impôs redução dos níveis salariais e defendeu a eliminação dos encargos sociais e a diminuição substantiva dos impostos, elementos constitutivos do financiamento da proteção social de diversos países. Mas para manter os salários reduzidos, se faz necessária a permanência do desemprego elevado: é por isso que o capital produtivo não estava interessado em promover nada parecido com uma situação de pleno emprego (Husson, 2003).

Ao mesmo tempo em que o desemprego voltou a fazer parte da vida do trabalhador, o movimento de massas (especialmente os trabalhadores sindicalizados), que havia sustentado o acordo do pós-guerra entre o capital e o trabalho, sofreu sucessivas derrotas. Uma idéia de seu impacto sobre a capacidade dos trabalhadores seguirem defendendo direitos e conquistas anteriormente alcançadas, é dada pela lembrança da emblemática derrota infringida pelo governo Thatcher aos mineiros ingleses e pelo significado simbólico e concreto da queda do Muro de Berlim e da dissolução da União Soviética. De maneira mais ou menos rápida, a depender do país, sindicatos antes aguerridos viram o número de sindicalizados cair vertiginosamente, mesmo entre aqueles com empregos relativamente estáveis. Para a maioria dos trabalhadores, a precarização das condições de trabalho constituía a norma, aumentando os empregos a tempo parcial, por prazo determinado e sem direitos (Mattoso, 1994).

\section{O Brasil diante dos novos constrangimentos: de um Estado desenvolvimentista a um Estado re- fém da dívida interna e externa}

A elevação da taxa de juros americana promovida pelo Federal Reserve no período 1979-1981 teve conseqüências dramáticas para os países do chamado Terceiro Mundo, especialmente os latino-americanos, que haviam sido incentivados a se aproveitar dos créditos associados à reciclagem dos petrodólares, viram, de repente, o serviço da dívida ser multiplicado por três ou mesmo por quatro. Essa situação deu origem ao que ficou conhecido como a crise da dívida.

No Brasil, a elevação da taxa de juros americana incidiu em meio a uma tentativa de re-equilibrar as contas externas mediante a promoção de uma recessão (a primeira ocorrida no pós-guerra). Tendo em vista a dificuldade crescente em obter financiamento do déficit das transações correntes, o que ficou evidente em 1979, o governo Figueiredo contraiu a demanda efetiva mediante, entre outras medidas, o controle das despesas públicas e das empresas estatais, a contração violenta do crédito (com exceção do dirigido à agricultura), o aumento do imposto sobre a renda e sobre os produtos importados. Essas medidas resultaram em queda do PIB em 3,1\% e um saldo positivo na balança comercial, promovido pelo aumento das exportações e pela redução das importações. Mas as taxas de juros internacionais aumentaram em quase $4 \%$, de forma que somente os juros da dívida passaram a represen$\operatorname{tar} 40 \%$ das exportações brasileiras.

No escopo desse artigo não há como se retomar a trajetória da economia brasileira nos anos que se seguiram. O que importa salientar é que desde a crise da dívida o país passou a conviver com uma restrição que lhe tomou (e toma) toda sua atenção. 
De 1982, quando o país recorreu formalmente ao Fundo Monetário Internacional (FMI), às sucessivas cartas de intenções (quando se dispunha a cumprir as condicionalidades impostas por este organismo), passando pelas várias tentativas de debelar o processo inflacionário galopante que acompanhou todo o processo de crise da economia brasileira, pela assinatura do acordo com o FMI, pelas privatizações das empresas estatais e pelo estímulo à entrada de capitais externos mediante a manutenção de elevada taxa de juros (o que, entre outros motivos, tornou a dívida interna um problema), assistiu-se a mudança do Estado brasileiro. O Estado desenvolvimentista " que havia sido elemento-chave do processo de industrialização, que havia investido em infra-estrutura e criado estatais produtoras de matérias-primas essenciais e que também tinha se preocupado em desenvolver o sistema público de proteção social " estava reduzido a poucas funções. A contenção do gasto público, primeira orientação que consta do Consenso de Washington de 1990 " dirigida tanto ao combate à inflação como à criação de um superávit primário (receitas menos despesas, sem levar em conta os juros da dívida interna) “ afastou o Estado de suas antigas funções, associadas ao período de desenvolvimentismo (1930 a 1979).

É nesse ambiente de novos constrangimentos para a economia brasileira e de um Estado manietado que a Constituição de 1988 definiu a saúde pública como um direito de todos e um dever do Estado. Ao contrário do que ocorreu quando da universalização da saúde nos países desenvolvidos europeus, o Brasil não mais crescia de forma duradoura, seu Estado estava encolhido vis-à-vis o seu passado, as taxas de desemprego mantinham-se em níveis muito elevados e a informalidade do trabalho crescia, superando a ocupação daqueles com direitos previdenciários e trabalhistas.

\section{A desigualdade como herança histórica do país}

Outra diferença do Brasil com relação aos países que implantaram a universalização da saúde no pós-guerra é a permanência de elevado grau de desigualdade. Essa desigualdade assume várias formas.

Em relação à desigualdade da renda, o Programa das Nações Unidas para o Desenvolvimento (PNUD, 2004), destaca que, em matéria de concentração de renda, o país somente perde para Serra Leoa, República Centro Americana, Suazilândia, Namíbia e Botswa- na. A concentração de renda é tal que, enquanto os $10 \%$ mais ricos ficam com $46,7 \%$ da renda, os $10 \%$ mais pobres se sustentam com apenas o, $5 \%$.

Analisando-se pelo lado das famílias, a renda das famílias mais ricas (renda familiar mensal, em 200o, acima de R\$10.982,00 de setembro de 2003), que totalizam 1,162 milhão, corresponde à $75 \%$ do total da renda nacional. Entre essas, as 5 .ooo famílias mais ricas absorvem 45\% da renda nacional (Pochmann e col., 2004). Essa situação, estrutural na sociedade brasileira, por diversos motivos, agravou-se entre 1980 e 2000. Em 1980 a renda média da população mais rica era 10 vezes maior do que a renda média da população brasileira. Vinte anos depois, essa relação era de 14 vezes, e de 80 vezes se comparada aos $20 \%$ mais pobres.

Mas de acordo com os dados da Pesquisa Nacional por Amostra de Domicílios (PNAD) de 2004, entre 2001 e 2004 a participação dos $10 \%$ mais pobres no total da renda nacional aumentou de $12,4 \%$ para $14,1 \%$ e a dos $50 \%$ mais ricos caiu de $47,3 \%$ para $44,3 \%$ (IBRE/FGV, 2006).

A esse quadro de extrema desigualdade se soma a existência de um enorme contingente da população situado abaixo da linha de pobreza. Segundo o Instituto Brasileiro de Economia (IBRE), da Fundação Getúlio Vargas, ao analisar os dados do Censo Demográfico de 2000, e ao adotar o critério de R\$60,oo per capita mensal como definidor da linha de pobreza, $35 \%$ da população brasileira (57,7 milhões de pessoas) está vivendo abaixo da linha de pobreza. Segundo esse instituto, as regiões mais pobres do país são a Norte e Nordeste, onde 13,8 milhões de pessoas vivem em situação de pobreza extrema; 26\% dos brasileiros nessa situação vivem nas zonas rurais. Na zona rural da região Norte, por exemplo, a renda média é de R\$ 19,67, a mais baixa do país.

Destaca-se ainda a desigualdade existente entre as regiões brasileiras. Sabe-se que as regiões norte, nordeste, sudeste, sul e centro-oeste possuem realidades bastante diversificadas, além de apresentarem densidade demográfica, atividade econômica predominante, nível de escolaridade de sua população, expectativa de vida, Índice de Desenvolvimento Humano (IDH) entre outros muito diferentes (IBGE, 2006; PNUD, 2003). Esse quadro é significativo para explicitar a heterogeneidade da desigualdade distribuída nas diversas áreas do território brasileiro.

Por sua vez, há outro aspecto específico da desi- 
gualdade que pode ser percebida tanto na oferta como na alocação dos recursos federais dos serviços e ações de saúde pública. Nos primeiros anos que seguiram à universalização da saúde no texto constitucional, os recursos do Ministério da Saúde (MS) foram alocados com base na produção dos serviços ambulatoriais e hospitalares, sancionando, portanto, as desigualdades da distribuição da oferta, sabidamente concentrada nas regiões mais ricas do país e nas capitais. A partir de 1997, iniciou-se um processo com vista a uma alocação mais eqüitativa dos recursos destinados às ações e serviços da atenção básica tendo como referência o mecanismo de remuneração per capita denominado Piso de Atenção Básica (PAB). Para isso definiu-se um valor mínimo (equivalente à média do gasto nacional) e um valor máximo (destinado aos municípios com gasto histórico acima da média nacional). Incentivos financeiros voltados para o desenvolvimento de programas específicos, entre os quais o Programa de Saúde da Família é o mais emblemático, complementavam essa estratégica. Segundo Porto e col. (2003), essas alterações na sistemática do financiamento da atenção básica resultaram numa partilha de recursos mais eqüitativa, melhorando a situação das regiões mais carentes. Mesmo assim, essa ação não foi suficiente para reverter o quadro de desigualdades no campo da atenção básica. Entre outros motivos, o critério adotado não daria conta do fato de as populações apresentarem composição diferenciada entre as regiões.

Do lado da produção de serviços, um simples olhar no número de consultas médicas e de internações hospitalares, entre 1996 e 2003, mostra que persistem diferenças entre as regiões, muito embora o nível de desigualdade tenha diminuído. Para se ter uma idéia, no tocante ao número de consultas (SUS) por habitante, os dados no Ministério da Saúde indicam que a pior região foi Norte, que passou de 1,4, em 1996, para 1,86, em 2003, enquanto a região Sudeste ampliou de 2,6 para 2,86. Já para o número de internações (SUS) por habitante, a situação é diferenciada. Isso porque a região Norte registrou maior resultado quando comparada à região sudeste.

\section{A construção da universalidade pelo sus e os constrangimentos econômicos}

A luta do SUS por recursos vem de longa data, podendo seu primeiro embate ser situado em 1993 quando 15,5\% da arrecadação da contribuição de empregados e empregadores, previstos no orçamento da União, não foi repassado para o MS (Marques e Mendes, 2005). Para o propósito deste artigo, no entanto, o importante é destacar aquelas situações em que os constrangimentos econômicos, especialmente os derivados do esforço de realização do superávit primário, refletiram-se em ações (vitoriosas ou não), que resultariam em menor disponibilidade de recursos para a saúde pública. As situações aqui descritas e analisadas referem-se, no entanto, praticamente ao âmbito federal, muito embora eventos semelhantes tenham ocorrido nas demais esferas de governo. Na realidade, a sociedade brasileira tem presenciado uma situação em que a área social, especialmente a da saúde, ao manter-se refém das metas e orientações econômicas, sofre avanços sobre seus recursos que podem estar prejudicando seu desenvolvimento.

a) Da aplicação do disposto na Emenda Constitucional (EC) 29/200o "A base de cálculo para os recursos daUnião

Em 1993, quando o Ministério da Saúde não deixou de receber os recursos previstos no orçamento da União, de origem nas contribuições de empregados e empregadores, levando a ocorrência do seu primeiro empréstimo junto ao FAT, os Deputados Eduardo Jorge e Waldir Pires elaboraram a Proposta de Emenda Constitucional 169 (PEC 169) que, em resumo, vinculava recursos para a saúde. Depois disso, várias outras propostas de vinculação foram elaboradas e discutidas no Congresso Nacional, mas somente em 2000 foi aprovada a emenda constitucional (EC-29). De acordo com a EC-29, a União deveria alocar, para o primeiro ano, pelo menos $5 \%$ a mais do que foi empenhado no orçamento do período anterior, e, para os seguintes, o valor apurado no ano anterior corrigido pela variação do PIB nominal.

Na aplicação dessa disposição, os Ministérios da Fazenda e do Planejamento, responsáveis pela elaboração da proposta orçamentária da União e pela aplicação da política econômica do país, interpretaram que o ano base seria o de 1999. Já para o Ministério da Saúde e para todos os organismos representativos da saúde pública, o ano base sobre o qual seria aplicado o adicional de $5 \%$ seria o de 2000 . 0 resultado dessa diferença de interpretação resultou que o orçamento do MS de 2001 foi diminuído em R\$ 1,19 bilhão, o que 
permitira dobrar os recursos gastos no Programa Agentes Comunitários, em 20oo. Para a equipe econômica do governo isso significou mais uma vitória no caminho do superávit primário acordado com o FMI.

\section{b) 0 descumprir do conceito de ações e serviços de} saúde nos estados e municípios

Alguns estados, para cumprirem o disposto na EC-29, de alocarem pelo menos $7 \%$ de suas receitas de impostos, compreendidas as transferências constitucionais, para o primeiro ano, sendo que esse percentual deveria aumentar anualmente até atingir, no mínimo 12\%, em 2004, incluíram indevidamente como despesas em ações e serviços de saúde os gastos com inativos da área da saúde, empresas de saneamento, habitação urbana, recursos hídricos, merenda escolar, alimentação de presos e hospitais de "clientela fechada" (como hospitais de servidores estaduais). Esses registros indevidos ocorreram apesar de anteriormente terem sido estabelecidos parâmetros que definiam quais ações e serviços poderiam ser considerados como gastos SUS. Esses parâmetros foram acordados entre o Ministério da Saúde, os estados e seus tribunais de contas, conforme a Resolução $\mathrm{n}^{0} \cdot 322$ do Conselho Nacional de Saúde, de 8 de maio de 2003, homologada pelo Ministro da Saúde.

Em alguns municípios o mesmo ocorreu, sendo o gasto com inativos da área da saúde entendido como despesa com saúde e o percentual de $15 \%$, estabelecido na EC-29 como o mínimo a ser aplicado " segundo a mesma base de cálculo dos estados “, exatamente o percentual a ser utilizado, mesmo que as necessidades exigissem gastos maiores.

c) Tentativas de redução do orçamento do Ministério da Saúde

A Lei de Diretrizes Orçamentárias (LDO) para o orçamento de 2004 previa que os encargos previdenciários da União (EPU), o serviço da dívida e os recursos alocados no Fundo de Combate e Erradicação da Pobreza fossem contabilizados como gastos SUS do Ministério da Saúde. Contudo, a forte reação contrária do Conselho Nacional de Saúde e da Frente Parlamentar da Saúde determinou que o Poder Executivo enviasse mensagem ao Congresso Nacional estabelecendo que, para efeito das ações em saúde, seriam deduzidos o EPU e o serviço da dívida. Em relação ao Fundo da Pobreza a mensagem era omissa. Essa omissão resul- taria na redução de 3.571 milhões de reais no orçamento SUS do Ministério da Saúde.

Apesar de diversos e intensos debates terem ocorrido entre entidades vinculadas ao SUS e o Ministério do Planejamento, nada foi modificado sobre essa questão. Somente após o parecer do Ministério Público Federal, contrariando a decisão presidencial e solicitando ao presidente Luís Inácio Lula da Silva que retirasse o veto ao dispositivo que esclarecia que os recursos do Fundo de Combate à Erradicação da Pobreza não poderiam ser contabilizados como gastos em saúde, sob pena de o orçamento aprovado vir a ser considerado inconstitucional, o governo recuou. Foi assim que a Lei $\mathrm{n}^{0}$. 10777, de 25 de novembro de 2003, contemplou, no parágrafo segundo do artigo 59, que o EPU, o serviço da dívida e as despesas do MS com o Fundo de Combate e Erradicação da Pobreza não fossem considerados ações e serviços públicos de saúde.

\section{d) A vinculação da EC 29 é objeto da atenção da área econômica}

Em fins de 2003, o governo federal encaminhou documento referente ao novo acordo com o Fundo Monetário Internacional, comunicando sua intenção de preparar um estudo sobre as implicações das vinculações constitucionais das despesas sociais "saúde e educação " sobre as receitas dos orçamentos da União, dos estados ou dos municípios. A justificativa apoiava-se na idéia de que a flexibilização da alocação dos recursos públicos poderia assegurar uma trajetória de crescimento ao País (Brasil, 2003).

No âmbito do SUS, a intenção do governo era tirar do MS a obrigação constitucional de gastar, tal como define a EC-29.

\section{e) 0 orçamento de 2006 do Ministério da Saúde em risco}

O projeto de Lei de Diretrizes Orçamentárias (LDO) para o orçamento de 2006, encaminhado pelo governo federal à Câmara, previa que as despesas com assistência médica hospitalar dos militares e seus dependentes (sistema fechado) fossem consideradas no cálculo de ações e serviços de saúde. Caso essa despesa fosse considerada, os recursos destinados ao Ministério da Saúde seriam diminuídos em cerca de 500 milhões de reais. Diante da declaração pública do MS, repudiando essa interpretação, e diante da mobilização das entidades da saúde, o governo federal foi obrigado a recuar, reformulando sua proposta. 


\section{O SUS e a melhora das condições de saúde}

Apesar das dificuldades inerentes ao quadro de desigualdade e das restrições impostas pelo lado da economia, parece não haver dúvida que a implantação do SUS foi acompanhada de melhora das condições de saúde do povo brasileiro, muito embora seja sabido que essas condições são resultado de múltiplos fatores, vários deles independentes do sistema de saúde em vigor. Noronha e col. (2005), ao analisarem as informações disponíveis no banco de dados do Ministério da Saúde (Datasus), destacaram uma série de indicadores dessa melhora. Entre eles salientam-se:

a) queda da mortalidade geral de 6,26 para 5,6, por mil habitantes, entre 1980 e 2002;

b) queda da mortalidade infantil de 45,3 para 25,1 por mil nascidos vivos, entre 1990 e 2002. Essa diminuição parece estar relacionada ao aumento da cobertura do saneamento básico, do abastecimento de água, dos serviços de saúde, dos programas de saúde maternoinfantil, das campanhas de vacinação e dos programas de aleitamento materno e reidratação oral.

c) mudança no perfil da mortalidade por causas. Em 1980, entre as cinco primeiras causas definidas de óbito estavam: doenças do aparelho circulatório, causas externas, doenças infecciosas e parasitárias, neoplasias e doenças do aparelho respiratório. Em 2000, as doenças infecciosas e parasitárias, diretamente relacionadas ao abastecimento de água, ao tratamento de esgoto sanitário e à disposição do lixo, deixaram de integrar as cinco primeiras causas.

É importante ainda mencionar o aumento da cobertura do Programa da Saúde da Família (PSF) e, no outro extremo de complexidade, a excelência reconhecida internacionalmente do Programa de DST/AIDS.

O PSF foi criado em 1994, mas somente a partir de 1998 consolidou-se como política prioritária do Ministério da Saúde. Entre 1998 e 2004, a proporção da população brasileira coberta pelo PSF passou de $6,58 \%$ para 40,0\%. O grau de cobertura variou entre as regiões do país e entre os municípios.

Em relação aos municípios, em 1998 apenas 9,41\% da população que residia em municípios com menos de 20 mil habitantes ( $80 \%$ dos municípios brasileiros) estava coberta pelo PSF. Contudo, ao longo dos anos acelerou-se essa cobertura e, em 2004, ela já atingia $65,29 \%$. Levando em conta a renda per capita mé- dia das famílias, verifica-se que, em 2004, os municípios mais pobres, com renda per capita média inferior ao salário mínimo, apresentavam cobertura de $58,49 \%$ e os com renda per capita média mais alta, igual ou maior que dois salários mínimos, a cobertura era de $24,89 \%$ (Brasil, 2006).

Em relação ao impacto do PSF, dois exemplos divulgados pelo Ministério da Saúde merecem ser citados. No que se refere à proporção de óbitos em menores de um ano de idade por causas mal definidas diz o MS: "a variação média anual desse indicador revela que quanto mais elevada a faixa de cobertura do PSF do grupo de municípios, maior a queda na proporção de óbitos infantis por causa mal definidas" (Op. cit., p. 9o). Em relação à taxa de mortalidade infantil, nos municípios com IDH baixo, a redução foi tanto maior quanto mais elevada foi a cobertura do PSF (Op. cit., p.171).

\section{Considerações Finais}

No Brasil, a introdução do direito à universalização da saúde pública deu-se em processo distinto e em ambiente diferente daqueles dos países desenvolvidos. 0 Brasil ao apenas inscrever esse direito na Constituição de 1988, constitui-se um caso tardio, tanto em referência ao tempo como ao momento da própria história do capitalismo em âmbito mundial que o apoiou.

Os anos de consolidação do sistema de proteção social brasileiro, ancorado no princípio da universalidade e na solidariedade entre as áreas que integram a Seguridade Social, firmaram-se no auge da nova fase do capitalismo, de dominância financeira. Nesse momento, o Welfare State no mundo desenvolvido já recebia críticas condizentes à nova lógica do capital financeiro portador de juros e começava a sofrer reformas, de menor ou maior envergadura. Por sua vez, as condições do mercado de trabalho revelavam-se completamente distintas do período dos "trinta anos gloriosos", isto é, emergiu o desemprego estrutural e, mais preocupante ainda, a precarização das relações de trabalho. Esse quadro problemático do mercado de trabalho também atingiu o Brasil, aprofundando seus traços precários históricos.

Como se viu neste artigo, o esgotamento do modelo do Estado brasileiro desenvolvimentista descortinouse a partir dos anos 1980, justamente quando as trans- 
formações do capitalismo contemporâneo ficaram evidentes. Entre os vários impactos que esse novo ambiente teve sobre a sociedade brasileira, um dos mais marcantes foi a substituição do Estado desenvolvimentista por um Estado refém da dívida interna e externa. Constrangido pelas exigências dos credores e pelos compromissos assumidos no momento de renegociações, em vários momentos dos últimos 25 anos, especialmente nos últimos governos, reduziu seu tamanho e buscou diminuir seus gastos, inclusive na área social. Nos anos 200o, a continuidade desse processo fez do superávit primário objetivo maior da equipe econômica.

Observou-se, portanto, que ao mesmo tempo em que o SUS era implantado, com base nos princípios de um sistema público e universal, agravava-se a crise fiscal e financeira do Estado, fazendo com que os governos federal e estadual limitassem o aporte de recursos para a saúde. Esse ambiente de encolhimento da capacidade do Estado e de ausência de crescimento econômico foi totalmente distinto do período em que ocorreu a universalização da saúde nos países desenvolvidos europeus.

Deve-se, por fim, acrescentar as problemáticas heranças estruturais da situação socioeconômica do país, que só se agravaram nas últimas décadas, exatamente no período de consolidação do direito universal à saúde. Tanto a permanência da pobreza como a alta desigualdade de renda e das regiões brasileiras, bem como a dificuldade de acesso aos serviços de saúde e a desigualdade na oferta e na alocação dos recursos federais das ações e serviços de saúde, indicam a especificidade e a diferença do Brasil em relação aos países que implantaram a universalização da saúde no pós-guerra.

Além disso, a desigualdade da oferta constitui um obstáculo para a plena universalização. Essa desigualdade é resultado da forma como o sistema de saúde público foi construído e de como a acumulação industrial localizou-se espacialmente.

A superação desse outro aspecto da desigualdade brasileira é tão difícil de ser enfrentado quanto os demais, configurando-se num desafio para a continuidade da implantação da universalidade da saúde pública no país. Contudo, como mencionado, apesar das dificuldades inerentes do quadro de desigualdade e das restrições impostas pelo lado da economia, a im- plantação do SUS foi acompanhada de melhora das condições de saúde do povo brasileiro, de ampliação do acesso, de diminuição das desigualdades regionais e de avanços relativos à garantia de recursos. Entre suas ações, destaca-se, no plano da atenção básica, o desenvolvimento do Programa de Saúde da Família.

\section{Referências}

AGLIETTA, M. Regulación y crisis del capitalismo. México, DF: Siglo Ventiuno, 1979.

BRASIL. Ministério da Fazenda. Carta de intenção. Brasília, DF, 2003. Disponível em: <http:// www.fazenda.gov.br>. Acesso em: 26 dez. 2004.

BRASIL. Ministério da Saúde. Saúde da família no Brasil: uma análise de indicadores selecionados 1998 - 2004. Brasília, DF, 2006.

BROUÉ, P. Révolution en Allemagne: 1917 - 1923. Paris: Minuit, 1971.

CASTEL, R. Les metamorphoses de la question sociale: une chronique du salariat. Paris: Fayard, 1995 .

CORIAT, B. L'atelier et le chronomètre. Paris: Christian Bourgois, 1982.

CHESNAIS, F. O capital portador de juros: acumulação, internacionalização, efeitos econômicos e políticos. In: CHESNAIS, F. (Org.). A finança mundializada: raízes sociais e políticas, configuração, conseqüências. São Paulo: Boitempo, 2005. p. 35-67.

D'IINTIGNANO, B. M. La protection sociale. Paris: Fallois, 1993.

ESCOREL, S.; NASCIMENTO, D. R.; EDLER, F. C. As origens da reforma sanitária do SUS. In: LIMA, N. T. et al (Org.). Saúde e democracia: história e perspectiva do SUS. Rio de Janeiro: Fiocruz, 2005. p. 59-81.

ESPING-ANDERSEN, G. As três economias politícas do welfare state. Lua Nova, São Paulo, n. 24, p. 85115, set. 1991.

ESPING-ANDERSEN, G. Policies against markets: the social democratic road to power. Princeton:

Princeton University, 1985. 
ESPING-ANDERSEN, G. Power and distributional regimes. Politics and Society, Princeton, v. 14, n. 2, p. 223-256, 1985 a.

GOUGH, I. The political economy of the welfare state. London: MacMillan, 1979.

HECLO, H. Modern social polities in Britain and Sweden. New Haven: Yale University, 1974.

HOBSBAWM, E. Adeus a tudo aquilo. In:

BLACKBURN, R. (Org.). Depois da queda: o fracasso do comunismo e o futuro da sociedade. Rio de Janeiro: Paz e Terra, 1992. p. 93-106.

HOBSBAWM, E. Era dos extremos: o breve século XX - 1914/1991. São Paulo: Cia das Letras, 1995.

HUSSON, M. Les casseurs de l'État social: des retraites à la sécu, la grande démolition. Paris: Découverte, 2003.

IBGE - INSTITUTO BRASILEIRO DE GEOGRAFIA E ESTATÍSTICA, Estudos \& Pesquisas - Informação Demográfica e Socioeconômica. $\mathrm{N}^{0} 15$. Disponível em: <http://www.ibge.gov.br/home/estatistica/ populacao/condicaodevida/indicadoresminimos/ sinteseindicsociais2004>. Acesso em: 26 fev. 2006 IBRE/FGV - INSTITUTO BRASILEIRO DE ECONOMIA/ Fundação Getúlio Vargas. Miséria em queda. [s.l.], 2005. Disponível em: <www.ibre.fgv.br >. Acesso em: 28 mar. 2006.

LENHARDT, G.; OFFE, C. Teoria do Estado e política social: tentativas de explicação político - sociológica para as funções e os processos inovadores da política social. In: OFFE, C. Problemas estruturais do Estado capitalista. Rio de Janeiro: Tempo Brasileiro, 1984. p. 15-16.

LIMA, N. T. et al (Org.). Saúde e democracia: história e perspectiva do SUS. Rio de Janeiro: Fiocruz, 2005.

MARQUES, R.; MENDES, A. Os dilemas do financiamento do SUS no interior da seguridade social. Economia e Sociedade, Campinas, v. 14, n. 1, p. 159-175, jan./jun. 2005.

MARSHALL, T. Cidadania, classe social e status. Rio de Janeiro: Zahar, 1967.

MARSHALL, T. Política social. Rio de Janeiro: Zahar, $1967 \mathrm{a}$.
MATTOSO, J. E. L. O novo e inseguro mundo do trabalho nos países avançados. In: OLIVEIRA, C. A. B. (Org.). O mundo do trabalho: crise e mudança no final do século. São Paulo: Página Aberta, 1994. p. 521-562.

MESA-LAGO, C. Desarrollo social, reforma del estado $y$ de la seguridad social, al umbral del siglo XXI. Santiago do Chile: ONU: Cepal, 2000.

NORONHA, J. C. de; PEREIRA, T. R.; VIACAVA, F. As condições de saúde dos brasileiros: duas décadas de mudanças (1980 - 200o). In: LIMA, N. T. et al (Org.). Saúde e democracia: história e perspectiva do SUS. Rio de Janeiro: Fiocruz, 2005. p. 153-192.

O'CONNOR, J. The fiscal crisis of the state. New York: St. Martin's,1973. OFFE, C. Capitalismo desorganizado: transformações contemporâneas do trabalho e da política. 2. ed. São Paulo: Brasiliense, 1994.

OLIVENNES, D. La societé de transferts. Le Debat, Paris, n. 69, p. 110-121, mars/avril 1992.

ORLOFF, A. S. The politics of pensions: a comparative analysis of Britain, Canada and the United States, 1880s-1940. Madison: University of Wisconsin, 1993.

PNUD - PROGRAMA DAS NAÇÕES UNIDAS PARA O DESENVOLVIMENTO. Atlas do desenvolvimento humano no Brasil. Brasília, DF, 2004. Disponível em: <http://www.pnud.org.br/atlas/tabelas/index.php>. Acesso em: 26 maio 2006.

POCHMANN, M. et al. Atlas da exclusão social. São Paulo: Cortez, 2004.v. 3.

PORTO, S. et al. Alocação eqüitativa de recursos financeiros: uma alternativa para o caso brasileiro. Saúde e Debate, Rio de Janeiro, v. 27, n. 65, p. 376-388, set./dez. 2003.

PRZEWORSKI, A. Capitalismo e social-democracia. São Paulo: Companhia das Letras, 1989.

ROSANVALLON, P. La crise de l'Etat-providence. Paris: Seuil, 1983.

SKOCPOL, T. Protecting soldiers and mothers. Cambridge, MA: Harvard University, 1992.

TITMUSS, R. Income distribution and social change. London: Allen \& Unwin, 1962. 
TITMUSS, R. Social policy. London: Taylor \& Francis, 1974 .

TITMUSS, R. Essays on the welfare state. London: Allen \& Unwin, 1976.
WEIR, M.; ORLOFF, A. S.; SKOCPOL, T. The politics of social policy in the United States. Princeton:

Princeton University, 1988.

WILENSKY, H. L.; LEBEAUX, C. N. Industrial society and social welfare. New York: Free Press, 1965. 